Vol. 67, N.o I05 (mayo 2015), I55-169.

\title{
ESQUEMA PRODUCTIVO, CONFLICTIVIDAD AMBIENTAL Y RESISTENCIA SOCIAL. EL MODELO AGROPECUARIO ARGENTINO ACTUAL
}

\author{
MARIANO TREACY \\ Universidad Nacional de General Sarmiento
}

Recepción manuscrito: 9 de enero de 2015

Aceptación versión final: 21 de marzo de 2015

\begin{abstract}
RESUMEN El presente artículo parte de la hipótesis de que la emergencia de conflictos socioambientales se vincula con el esquema productivo vigente en la Argentina. Desde un marco teórico que incluye los aportes de la Ecología Política, de la Teoría de la Dependencia y del Análisis del Sistema Mundo, se propone elucidar el vínculo entre la organización de movimientos sociales, la conflictividad socioambiental y el modelo agropecuario en la Argentina (20022013). Se caracteriza las transformaciones del esquema productivo agrícola, vinculándolo con la emergencia de conflictos sociales y de movimientos sociales, tomando al Movimiento Campesino de Santiago del Estero - Vía Campesina como ejemplo.
\end{abstract}

palabras ClaVe Dependencia, neoextractivismo, monocultivo, conflictividad ambiental, movimientos sociales, reforma agraria.

ABSTRACT This article suggests that the emergence of environmental conflicts is linked to the current scheme of production in Argentina. From a theoretical framework that includes the contributions of political ecology, the dependency theory and world-system analysis, this paper analyzes the link between the organization of social movements, the socio-environmental conflicts and the agricultural model in Argentina (2002-2013). It characterizes the changes in the agricultural production system in Argentina, linking it to the emergence of social conflicts and social movements. The Peasant Movement of Santiago del Estero - Via Campesina (MOCASE-VC) is used as case study.

KEYwORDS Dependency, neo-extractivism, monoculture, environmental conflicts, social movements, agrarian reform.

CODIFICACIÓN JEL O13, O30, O180, Q15.

\section{INTRODUCCIÓN}

El conflicto social ha expresado históricamente las tensiones propias del modo de producción, un conflicto que es inherente a la forma en que se organiza la sociedad y se distribuye la propiedad, el trabajo y la riqueza. Sin embargo, una de las novedades históricas de nuestros tiempos es que el conflicto esté expresando un antagonismo creciente ente la acumulación del capital 
y la salud del medio ambiente, que es el sustrato vital sobre el que se sostienen todas las construcciones sociales y culturales (O’Connor, 2001).

En la última década se han registrado en América Latina numerosos - y crecientes - conflictos que vinculan precisamente los problemas ambientales con el acceso al territorio y el modo en que se produce y se apropian los beneficios derivados de esa producción. La resistencia al avance de proyectos de minería y megaminería, de la agroindustria, de la explotación de hidrocarburos no convencionales, de la deforestación, de la privatización y contaminación de los cursos de agua, de las empresas pasteras, etc. (Delgado Ramos, 2013) permiten establecer una relación entre algunos aspectos del modelo productivo y la vulneración de ciertos derechos que se exigen mediante el conflicto. La expansión de las ramas extractivas ${ }^{1}$ de la economía se ha vuelto una variable relevante para explicar la emergencia de los conflictos socioambientales y en la Argentina en los últimos años (Merlinsky, 2013). La orientación extractiva del modelo productivo de los últimos años, como afirma Gudynas (2009):

[...] Se sostiene sobre la apropiación de la Naturaleza, que alimenta un entramado productivo escasamente diversificado y muy dependiente de una inserción internacional como proveedores de materias primas, y que si bien el Estado juega un papel más activo, y logra una mayor legitimación por medio de la redistribución de algunos de los excedentes generados por ese extractivismo, de todos modos se repiten los impactos sociales y ambientales negativos. (p. 188)

Las características que asume el agronegocio ${ }^{2}$ en la Argentina en la actualidad están signadas por la adopción del paquete tecnológico en los 90, que introdujo la semilla de soja Roundup Ready (RR) genéticamente modificada, los fertilizantes y la siembra directa. Estas modificaciones, conocidas como «revolución verde», provocaron una mejora considerable en lo que respecta al rinde por hectárea (que aumentó a una tasa anual acumulativa del 1,9\% entre 2000 y 2010) y permitieron expandir la superficie sembrada desde las 20 millones de hectáreas de la cosecha 1993/1994 hasta las 30 millones de hectáreas de 2013, lo que representa un récord histórico. Al apuntalamiento de los márgenes de ganancia que brotó de este proceso se sumaron, la devaluación en la salida de la crisis del 2001-2002 y los elevados precios de los productos agrícolas en el mercado mundial (que en el caso de la soja pasaron de 190 a 555 dólares por tonelada entre 2001 y 2013) (CIFRA, 2011).

Entre el 2002 y 2013 no solo la superficie sembrada en la Argentina se incrementó considerablemente (donde la soja llegó a acaparar el 60\%), sino que también se expandió la producción (desde 67 millones de toneladas en 2001 hasta 102 millones en 2013) y la exportación de cereales y oleaginosas. Lo mismo sucedió con los márgenes brutos de producción, que pasaron de 209 dólares por hectárea entre 1991 y 2001 a 272 dólares entre 2002 y 2012. En adición a estos beneficios, se suman desde 2002 las ganancias patrimoniales que provienen del incremento en el valor de las tierras agrícolas pampeanas, que en la Zona Núcleo aumentaron de un precio promedio por hectárea de 3109 dólares entre 1991-2001 a 16000 dólares en 2013 (CIFRA, 2011). A pesar de su evidente aporte en materia de crecimiento económico y su contribución al equilibrio macroeconómico en los últimos años, sin embargo, la expansión del agronegocio en la Argentina ha estado vinculada también al recrudecimiento del conflicto social y a la conformación de movimientos sociales como el Movimiento Campesino de Santiago 
del Estero - Vía Campesina (MOCASE-VC), cuya organización responde a la resistencia al avance de la frontera agrícola y la lucha por el respeto de su territorio y de su forma de organización de la producción y el consumo.

El presente artículo tiene como punto de partida la hipótesis de que la emergencia de conflictos socioambientales se vincula íntimamente con el esquema productivo vigente en la Argentina en la actualidad. Desde un marco teórico que incluye los aportes de la Ecología Política, de la Teoría de la Dependencia y del Análisis del Sistema Mundo, en el presente trabajo se propone el objetivo general de elucidar el vínculo existente entre la organización de movimientos sociales, la conflictividad socioambiental y el modelo agropecuario en la Argentina (2002-2013). En este trabajo se espera caracterizar las transformaciones del esquema productivo agrícola en la Argentina vinculándolo con la emergencia de conflictos socioambientales y de movimientos sociales, tomando al Movimiento Campesino de Santiago del Estero - Vía Campesina (MOCASE-VC) como caso testigo.

Para ello, en la sección 2 del trabajo se realiza una breve caracterización de la dinámica de acumulación mundial y de la inserción de la Argentina en la división internacional del trabajo respondiendo a los interrogantes sobre la relación que existe entre el Sistema Mundo, la división internacional del trabajo y el rol de Argentina como productora y proveedora de materias primas para el mercado mundial. En la sección 3, se procede a describir sucintamente el modelo económico en la Argentina de la posconvertibilidad (2002-2013), caracterizando el vínculo existente entre el esquema productivo agropecuario y las problemáticas socioambientales que emergieron. Por último, en la sección 4 se presenta un estudio de conflictos sociales vinculados al modelo agropecuario y se realiza un breve análisis de la conformación del MOCASE-VC como uno de los movimientos sociales asociados al conflicto sobre el modelo agropecuario.

\section{DEPENDENCIA, ACUMULACIÓN POR DESPOSESIÓN Y NEOEXTRACTIVISMO}

El moderno Sistema Mundial se constituye hacia fines del Siglo XV, con la incorporación de América a las redes mundiales de producción y circulación mercantil. Desde entonces hasta nuestros días, el espacio de valorización del capital se ha extendido hasta las regiones más remotas, donde cada lugar geográfico específico, con mayor o menor autonomía relativa, cumple un rol que se relaciona en mayor o menor grado con la configuración de la Economía-Mundo, que se define como una gran zona geográfica dentro de la cual existe una división del trabajo y, por lo tanto, un intercambio significativo de bienes así como también un flujo incesante de capital y trabajo (Wallerstein, 2006).

La forma concreta que asumen las relaciones de producción y circulación en un país determinado se encuentra inscrita, por un lado, en el modo que de acumulación a escala mundial, generalmente impulsado por un país hegemónico, y también en la estructura de clases interna y la configuración específica del estado-nación (Arrighi, 1999). La dependencia es un concepto que refleja la articulación y compromiso entre el modo de acumulación a escala mundial y la estructura interna de los espacios geoeconómicos nacionales, y se define como una situación en la que algunos países pueden expandirse por su propia 
iniciativa mientras que otros pueden hacerlo sólo como reflejo (Dos Santos, 1971). En esta interacción jerárquica, los países centrales son aquellos que pueden expandirse y ser autogeneradores de su ciclo de reproducción del capital mediante el control monopolístico de algunos mercados, la exportación de capital y de empréstitos y el control del conocimiento y los avances tecnológicos. Los países dependientes, por lo contrario, se ven subordinados a las necesidades de acumulación de los países centrales, tanto en materia comercial como en materia productiva, financiera y tecnológica (Dos Santos, 1971).

Tanto desde el Análisis del Sistema Mundo ${ }^{3}$ como desde la Teoría de la Dependencia ${ }^{4}$ se propone una visión en donde las trayectorias de cada espacio geoeconómico se vinculan dialécticamente con la totalidad del Sistema y con el resto de sus componentes. La comprensión de la economía mundo como un sistema permite analizar los procesos ocurridos en cada espacio nacional en su correspondencia con procesos históricos vinculados en la globalidad del sistema. Con esta misma lógica, los procesos que se dan a escala subnacional, también se configuran condicionados por las características que asume el patrón de reproducción del capital a escala nacional (Osorio, 2004) y su vinculación con la Economía Mundial. En el caso de este estudio, la expansión de la frontera agrícola en las provincias argentinas de Córdoba, Santiago del Estero, Salta, Chaco y Formosa, por mencionar solo algunas, ha estado relacionada con el giro ecoterritorial postneoliberal hacia el «Consenso de los Commodities» (Svampa, 2012) que ha caracterizado a la mayoría de los países de la región.

Harvey (2004) actualiza el concepto de «imperialismo» de forma tal que nos permite iluminar los lazos que vinculan la emergencia de los conflictos en torno a cuestiones sociales y ambientales con las formas que ha adoptado la producción y la distribución en la periferia y las condiciones de la economía mundial que generan y reproducen estas situaciones de desigualdad. Una de las expresiones de este «nuevo imperialismo», como lo denomina, ha sido la profundización de los mecanismos de acumulación por desposesión, que dieron respuesta a las dificultades que estaba experimentando la acumulación por las vías «tradicionales» de la reproducción ampliada.

La acumulación por desposesión (Harvey, 2004), como lo fuera la llamada «acumulación originaria o primitiva» (Marx, 2000) en los comienzos del capitalismo, se origina en la reorganización territorial del trabajo y la reconfiguración de los espacios dinámicos de acumulación del capital, expandiendo las relaciones de producción y propiedad capitalistas a espacios que antes habían permanecido ajenos. La mercantilización y privatización de la tierra y de los recursos naturales, la expulsión de poblaciones campesinas e indígenas y su conversión en asalariados y la disolución de formas de producción y consumo alternativas, configuran el resultado de este mismo proceso, en el que el capital añade esferas a su necesidad de valorización. Esta expansión se da precisamente mediante la desposesión, lo que origina una vulneración de los derechos humanos que emerge como un conflicto. Asimismo, la explotación intensiva de los recursos naturales, el despojo y la apropiación privada (y extranjera) de los frutos de la producción han generado un impacto ambien$\mathrm{tal}^{5}$ que ha generado un caldo de cultivo que permitió la emergencia de conflictos vinculados con la defensa del medio ambiente. Como señalan Seoane, Taddei y Algranati (2013): 
Podríamos vislumbrar a la cuestión ambiental como expresión de la contraposición existente entre las promesas de bienestar asociadas históricamente al progreso y desarrollo de la sociedad capitalista y la realidad efectiva de deterioro y destrucción de las condiciones de la vida y el ambiente. (p. 243)

El modelo «neoextractivista» es en la actualidad el que permite una especie de pacto en el cual se han garantizado mejoras en las condiciones de vida de las mayorías urbanas mediante la captura de una porción de la renta generada por las actividades vinculadas a la actividad extractiva que generan resistencia en ámbitos periurbanos y rurales. Este esquema productivo y de captura de renta, que se ha legitimado socialmente como el único capaz de brindar «progreso» a la población, se ve impulsado en América Latina en el contexto actual tanto por un cúmulo de megacorporacicones y grupos transnacionales mineros, petroleros, gasíferos, de agua, del agronegocio, la biotecnología y la biogenética, como por grupos económicos «nacionales» transnacionalizados - las llamadas translatinas - ${ }^{6} \mathrm{y}$ empresas locales proveedoras y subsidiarias de estas últimas. La estrategia neoextractivista, por lo tanto, no se expresa únicamente en el perfil productivo y exportador, sino que también configura las relaciones políticas, económicas y sociales subnacionales, internacionales y las estrategias de integración regional. ${ }^{7}$

La organización de movimientos sociales como un emergente de los conflictos existentes en torno a los procesos de acumulación por desposesión se inscriben en la lógica de un sistema mundial jerarquizado donde la división internacional del trabajo ha señalado que los países de la región en general, y la Argentina en particular, se inserten como productores y exportadores de materias primas con escaso procesamiento a nivel local en este nuevo «consenso de los commodities» (Svampa, 2012).

\section{EL ESQUEMA PRODUCTIVO AGROPECUARIO Y EL MODELO ECONÓMICO ARGENTINO ACTUAL}

El proyecto iniciado en 2002 en la Argentina permitió no solo la recuperación de la tasa de ganancia y la relegitimación del sistema político sino también una relativa revalorización de la autonomía del Estado ${ }^{8}$ y cierta capacidad de recepción y canalización de las demandas populares por las vías institucionales. Desde 2002 se asiste en la Argentina a un «nuevo patrón de crecimiento» caracterizado por la «reversión del proceso de destrucción del tejido industrial que derivó en niveles inéditos de desocupación y pobreza en el país» (p. 37) y en la reversión del proceso de «reducción de la participación de las manufacturas en el PIB, del crónico déficit fiscal y comercial, del crecimiento de la deuda externa y de la sistemática pérdida de reservas internacionales» (CENDA, 2010, p. 38). Como señalan Azpiazu, Manzanelli y Schorr (2011), desde 2002 hasta la fecha asistimos a la alteración de «muchos de los aspectos críticos del modelo de acumulación vigente entre 1976 y 2001» (p. 13). Esta alteración de los aspectos críticos, está reflejada en:

la redefinición de los liderazgos sectoriales, la reversión (aunque acotada) del proceso de desindustrialización, la importante creación de puestos de trabajo y la consiguiente mejora en diversos indicadores sociales [...], el 'desendeudamiento', la reestatización del sistema previsional y los 'superávits gemelos' (externo y fiscal). (p. 13) 
Sin embargo, entre las continuidades o «nudos problemáticos», Azpiazu, Manzanelli y Schorr (2011) señalan:

la ausencia de cambio estructural en el perfil de especialización productivo-industrial y de inserción del país en la división internacional del trabajo, las ostensibles inequidades territoriales y regionales, la fuerte oligopolización de los mercados, la persistencia de la fuga de capitales locales al exterior [...], el elevado nivel de empleo precario e informal, la vigencia de salarios muy reducidos en términos internacionales e históricos [...] y las presiones inflacionarias. (pp. 13-14)

El rol del Estado argentino en la promoción del esquema neoextractivista no ha tenido una dirección unívoca, ${ }^{9}$ sino que ha estado permeado por la correlación de fuerzas. Sin embargo, el modelo de agricultura industrial vigente en la Argentina en la actualidad representa una de las principales continuidades con el que existía en los años 90, y la expansión del monocultivo y los agronegocios tienen comprobados impactos negativos sobre la sociedad y el medio ambiente (Carrasco, A., Sánchez, N. y Tamagno, L., 2012). El modelo de crecimiento implementado en la última década en la Argentina sostuvo los superávits gemelos (fiscal y externo) en gran parte gracias a la expansión de la producción agrícola, la implementación de derechos de exportación y al aumento de los términos del intercambio - los precios de los productos de la canasta exportadora en relación a los precios de los productos de la canasta importadora-. Entre 2002 y 2013 la recaudación en concepto de derechos de exportación ha representado en promedio el 11,3\% de los ingresos fiscales corrientes (Ministerio de Economía, 2014).

Para Skill y Grinberg (2013), el modelo productivo en la Argentina se puede caracterizar como «extractivista exportador» (p. 95). Uno de los principales aspectos es la expansión del monocultivo hacia nuevas fronteras, facilitado por la introducción del paquete tecnológico. Entre los elementos que contribuyen a la caracterización del modelo del agronegocio como aquel centrado en la producción agrícola bajo una lógica extractiva, ${ }^{10}$ Giarraca menciona las actividades con un elevado consumo de recursos no reproducibles - como el agua-, que desplazan actividades preexistentes porque requieren escalas de producción mucho mayores, que utilizan «tecnologías de punta» (p. 330), que se localizan territorialmente porque dependen de la presencia de recursos naturales, que generan elevados valores de cambio y grandes rentabilidades asociadas a rentas pero escasos valores de uso para la comunidad, que se vinculan con el interés de grandes corporaciones, que desplazan trabajadores rurales, campesinos e indígenas, y que se orientan fundamentalmente hacia las exportaciones.

Uno de los factores que permite comprender las posibilidades del campo argentino en la actualidad es la transformación estructural experimentada por el sector en los años 90, que dio lugar a lo que se conoce como «nuevo agro» argentino (Kejsefman, 2014). La «revolución verde» comienza en los 70 cuando se produce el proceso de «agriculturización» derivado de la introducción de nuevas variedades de cereales y oleaginosas y de biotecnología aplicada a la producción agrícola que permite desarrollar el doble cultivo anual trigo/soja, desplazando a la producción ganadera y sustituyendo progresivamente la producción de maíz y sorgo. Este proceso de cambio tecnológico aplicado al agro y modificación del paradigma tecnoproductivo madura en los años 90 con la introducción de un "paquete tecnológico» que incluye semillas 
genéticamente modificadas (GM), siembra directa ${ }^{11}$ y agroquímicos — fertilizantes, herbicidas, plaguicidas- (Teubal, 2006). La difusión del paquete tecnológico, en conjunto con la difusión de maquinaria agrícola y mecanismos radarizados y computarizados de control, permitieron la expansión de la productividad y el corrimiento de la frontera agrícola (Seoane, Taddei y Algranati, 2013).

Una de las principales consecuencias del nuevo modelo tecnoproductivo agrícola fue el aumento de la productividad agrícola, que se ve reflejado en el incremento de la producción: de 40 a 104 millones de toneladas entre 1993 y 2013. Este aumento de la producción respondió también a la expansión de la superficie sembrada — desde las casi 20 millones de hectáreas de la cosecha 1993/1994 hasta las casi 35 millones de hectáreas de 2013-, facilitada por los nuevos métodos agronómicos y por los nuevos precios de los productos, que permitieron producir allí donde antes era inviable técnicamente y no rentable económicamente. El aumento del rendimiento respondió también a la introducción del doble cultivo con la combinación soja/ trigo en la misma campaña agrícola. Asimismo, contribuyeron en la misma dirección la introducción de agroquímicos — herbicidas, fertilizantes, plaguicidas-. Por último, el otro factor que permitió incrementar la producción pese a la reducción de la superficie sembrada fue la potenciación de la forma de trabajo del contratista de maquinaria, que permitió un uso intensivo de los bienes de capital existentes y una reducción de los costos (Basualdo, 2010).

Los guarismos récord de superficie sembrada, de producción y de exportación estarían reflejando el salto en el rinde por hectárea que, en el caso de la soja, alcanza un promedio de 25,6 quintales por hectárea llegando a un total de 49 millones de toneladas - 22,5\% respecto a 2012- y en el caso del maíz un rinde promedio de 72,4 quintales por hectárea llegando a un total de 25 millones de toneladas - 15\% respecto a 2012-. Este incremento en la producción se condice con la elevada rentabilidad que percibe el sector en un contexto internacional en el que se mantuvieron elevados los precios de las commodities, se redujeron los costos en dólares de los insumos y mejoró considerablemente el rendimiento por hectárea de la producción.

La estructura productiva agraria Argentina se encuentra fuertemente concentrada, tanto si se considera en términos de propiedades como también, y sobre todo, en términos de producción. Más del 85\% de la producción agrícola se concentra en los mismos grupos tradicionales pampeanos desde hace un siglo, a través de sus propias propiedades y a través de propiedades arrendadas. Además, casi un tercio de la superficie pampeana está en manos de los grandes propietarios y de grupos agropecuarios con más de 20 mil hectáreas cada uno. El proceso de concentración territorial se expresa en que en la actualidad el 82\% de los productores ocupan solo el $13 \%$ de la tierra, mientras que el $4 \%$ de los productores ocupan el $65 \%$ de la tierra. Asimismo, seis grandes exportadoras dominan todo el largo de la cadena de valor de la producción de soja y el 50\% de las tierras están en manos del 2\% de los propietarios (CIFRA, 2011). La revolución agrotecnológica también imprime nuevas relaciones de gobernanza en las cadenas productivas, en las que las multinacionales semilleras, proveedoras de agroquímicos y exportadoras de granos como Monsanto, Syngenta y Bayer han ganado un peso considerable (Kejsefman, 2014).

El incremento de la producción, la expansión de la frontera agrícola, la concentración de la tierra y de la producción y el peso de las grandes empresas transnacionales han provocado 
que se tensionen los límites existentes con las organizaciones de los campesinos e indígenas que intentan subsistir con sus métodos de producción y distribución propios. La revolución tecnoproductiva y el crecimiento económico, por lo tanto, no son fenómenos neutrales sino que como todo proceso de esta magnitud conllevan fuertes efectos sobre la democracia económica, la sustentabilidad ambiental y la justicia social. El esquema productivo descrito refleja entonces una dependencia estructural de la economía argentina con relación a la extracción, explotación y exportación de los recursos primarios, que ha quedado plasmada en el nuevo «consenso de los commodities» que da forma a la estrategia neoextractivista. Esta situación ha penetrado de manera conflictiva relaciones de producción y distribución que hasta el momento permanecían ajenas a esta lógica, y ha situado en la agenda la cuestión ambiental, lo que ha permitido el florecimiento de organizaciones que se resisten a estas tendencias.

\section{CONFLICTIVIDAD AMBIENTAL Y MOVIMIENTOS SOCIALES}

El proceso de expansión de la frontera agrícola responde a una necesidad creciente de concentración y centralización de la tierra que impone la competencia internacional, los estándares de producción y los elevados precios relativos de los productos que cotizan en el mercado mundial. La expansión de la frontera de producción agrícola en los últimos años ha producido, a la vez que aumentó la generación de riqueza material con la aplicación de la ciencia y la tecnología, un incremento de la conflictividad social en torno a la protección de los recursos naturales y de los derechos de propiedad de los campesinos e indígenas sobre sus posesiones.

El modelo productivo también requiere un creciente empleo de agroquímicos, que ha despertado fuertes controversias debido a los riesgos que genera sobre la salud y el medio ambiente. ${ }^{12}$ El caso emblemático es el del barrio Ituzaingó Anexo en la provincia de Córdoba, donde se demostró con evidencia que los agroquímicos que se utilizan en las fumigaciones representan un riesgo para la salud como abortos espontáneos, problemas respiratorios, cáncer, malformaciones, afecciones cutáneas y enfermedades de efectos crónicos; para el ambiente, como degradación del suelo, deforestación, contaminación del agua, degradación ambiental, destrucción de biodiversidad; y para la sociedad, mediante la expulsión de comunidades rurales (Skill y Grinberg, 2013). El crecimiento de las plantaciones de soja ha provocado deforestación, ${ }^{13}$ la degradación y pérdida de materia orgánica, desertización y salinización de los suelos. La búsqueda de rentabilidades de corto plazo y la presión por las ganancias ha generado que no se realicen las precauciones necesarias para preservar el suelo, desarrollándose plagas, agentes patógenos y malezas y la acidificación de los suelos. ${ }^{14}$ (Astarita, 2008)

En los últimos años hemos tenido una serie de conflictos que nos marcan la pauta de las problemáticas sociales y ambientales que se derivan del modelo de crecimiento actual. Merlinsky (2013) define al conflicto como un «verdadero medio de expresión y de toma de la palabra, una modalidad de intercambio entre los actores donde se construyen escenarios en los que confrontar discursos» (p. 39). Desde su perspectiva, los conflictos ambientales ponen en cuestión precisamente las relaciones de poder que son aquellas que «facilitan el acceso a esos recursos, que implican la toma de decisiones sobre su utilización por parte de algunos actores y la exclusión de su disponibilidad para otros actores» (p. 39). 
Una de las consecuencias manifiestas de la expansión de la frontera agrícola y del monocultivo es que se ha potenciado la tradicional producción extensiva del agro pampeano, debido principalmente a las economías de escala que reducen el costo por hectárea a medida que se incrementa la superficie sembrada. Esto ha provocado un cambio en las relaciones de poder al interior de la cadena de valor agropecuaria beneficiando principalmente al gran terrateniente pampeano, cuyos efectos se reflejan por un lado en la mayor concentración de la tierra y por el otro en un vertiginoso ritmo de expulsión de trabajadores rurales y campesinos e indígenas (Basualdo, 2010). Como parte de este proceso, en los últimos 40 años la cantidad de productores se ha reducido a la mitad, se ha desplazado a los conurbanos a una población no menor de campesinos, trabajadores rurales e indígenas, lo cual ha derivado también en problemáticas sociales y ambientales en los espacios urbanos (Aranda, 2013).

De esta forma, con la instrumentación de este modelo, la expansión del agronegocio entró en tensión con modos de producción alternativos, principalmente campesinos e indígenas sin títulos de propiedad pero con posesión veinteañal de sus tierras. ${ }^{15} \mathrm{La}$ imposición en concreto de la lógica de la acumulación por despojo para desarrollar el agronegocio involucra procesos de violencia estatal y paraestatal que, lejos de representar casos aislados, en muchas regiones representan una cuestión cotidiana. Esta lógica llevó muchas veces a desalojos violentos e ilegales, lo que ha generado una serie de conflictos que ha llevado a la organización de movimientos sociales.

Como respuesta a este proceso se han organizado fuertes resistencias sociales. En la Argentina, una de las organizaciones más importantes en la actualidad es el Movimiento Nacional Campesino Indígena (MNCI), una de cuyas expresiones territoriales es el Movimiento Campesino de Santiago del Estero - Vía Campesina (MOCASE-VC). El MOCASE se constituye formalmente el 4 de agosto de 1990, como el producto de la acumulación histórica de las luchas campesinas en la región —en la actualidad más de nueve mil familias participan en él一. A nivel regional e internacional, el MOCASE participa de la Coordinadora Latinoamericana de Organizaciones de Campo (CLOC) y de la Vía Campesina (VC).

Este movimiento representa la resistencia al avance del modelo del agronegocio y propone un modelo societal de producción, de circulación y de consumo alternativos y la defensa de actividades locales. Su lucha radica principalmente en la defensa del territorio, el monte, los boques nativos y naturales y de los derechos de los campesinos e indígenas frente al avance de proyectos productivos basados en el agronegocio, que se orientan en función de los criterios de propiedad y rentabilidad privadas y que requieren un proceso agricultura intensiva sobre suelos no aptos ya que tienen bajo contenido de materia orgánica. Este proceso que provoca permanentes desalojos y migraciones forzosas, desmonte, ${ }^{16}$ lavado del suelo y desertificación, avance del monocultivo y de la concentración y extranjerización de los recursos naturales para la exportación. Otro de los componentes que permiten la emergencia de la organización del movimiento social es la competencia por el agua en las zonas de riego, que ha generado la eliminación de variedades autóctonas de hortalizas y frutales, y ha provocado la salinización de suelos. ${ }^{17}$

El conflicto en el territorio se da entre los campesinos e indígenas organizados frente a los terratenientes y empresarios agrícolas, madereros, mineros y petroleros, que en muchos casos 
cuentan con el apoyo del poder político, judicial y policial local. ${ }^{18}$ En este conflicto, los campesinos e indígenas exigen el reconocimiento de sus derechos a la regularización de la tenencia de la tierra y al uso del agua, y a la jerarquización de la función social de la tierra y el agua por sobre la función empresarial. Junto a estos derechos, exigen también aquellos garantizados en el art. 75 inciso 17 de la Constitución Nacional ${ }^{19}$ y en las leyes 24071 y $26160,{ }^{20}$ sobre el respeto a la identidad de los pueblos indígenas, sus posesiones comunitarias y su derecho a acceder a tierras que les permitan el desarrollo humano. Como propuesta de modelo alternativo al del agronegocio, el MOCASE-VC incuba nuevas relaciones de producción postulando un modelo productivo donde se complemente el esquema actual con un desarrollo de la agricultura urbana, las huertas agroecológicas y los mercados urbanos, y donde se garantice la permanencia en el campo de las comunidades campesinas e indígenas, desarrollando infraestructura educativa rural y tecnologías apropiadas a este tipo de producción. ${ }^{21}$

Para lograr modificar la situación productiva y distributiva actual, la propuesta del MOCASE-VC desarrolla los conceptos de Soberanía Alimentaria ${ }^{22}$ y de Reforma Agraria Integral. La soberanía alimentaria implica un modelo basado en la agricultura comunitaria, distribuyendo tierras, agua y herramientas y facilitando la infraestructura necesaria para su funcionamiento, privilegiando mercados locales y produciendo alimentos nutritivos, accesibles y producidos de forma sostenible y ecológica. La Reforma Agraria Integral es por su parte la «regularización de la tenencia de la tierra de las comunidades campesinas indígenas de manera colectiva e inembargable. Es cambiar las leyes de uso del agua para que sean más justas [...] es jerarquizar la función social de la tierra y el agua y dejar de considerar a los bienes naturales como mercancías» (Falta Menos, 2011, p. 11).

\section{REFLEXIONES FINALES}

En el presente artículo se intentó verificar la hipótesis de que la emergencia de conflictos socioambientales se encuentra íntimamente vinculada con el esquema productivo vigente en la Argentina en la actualidad, y que esto se refleja en el estallido de conflictos ambientales y en la proliferación de movimientos sociales como el Movimiento Campesino de Santiago del Estero -Vía Campesina (MOCASE-VC), que se ha tomado como caso testigo. Las tendencias recientes de la acumulación capitalista a escala global se describieron a través del concepto analítico de «acumulación por desposesión o por despojo», que se caracteriza por un proceso de creciente mercantilización y privatización de la tierra que lleva a la expulsión forzosa y violenta de las comunidades campesinas e indígenas. Lo mismo ocurre con la fuerza de trabajo y las formas de producción y consumo alternativas, que se ven subsumidas por la fuerza del capital y sus necesidades de valorización constante.

Este proceso de acumulación por desposesión se expresa en un plano más concreto en la Argentina en la consolidación de un modelo agropecuario «neoextractivista» en los últimos veinte años. Junto con las actividades extractivas «tradicionales», que son aquellas que explotan bienes no renovables como el petróleo, el gas o los minerales, el «neoextractivismo» también engloba a otras actividades productivas sobre bienes «renovables», pero en las que la tasa de extracción se vuelve más alta que la tasa de renovación del recurso, como en el caso del 
agronegocio. El agronegocio expresa un proceso mediante el cual la mercantilización de la tierra y la producción agropecuaria se introducen plenamente en el circuito global de valorización capitalista, para lo que se requiere un proceso de desmonte, deforestación y pérdida de servicios ambientales que quiebran el equilibrio ecológico de vastos sectores del país.

La consolidación de este modelo productivo se inscribe dentro de los patrones de dependencia histórico-estructural condicionados por la división internacional del trabajo y por la estructura económica y social interna. Así, la privatización y mercantilización de los bienes comunes, en conjunto con la orientación de la inversión extranjera directa y los proyectos de infraestructura y desarrollo en curso, dan cuenta en su conjunto de la orientación del esquema productivo hacia la extracción, explotación y exportación de recursos naturales con escaso valor agregado y contenido tecnológico. El proceso de expansión de la frontera agrícola, la concentración de la tierra y del poder económico ha generado como contrapartida el surgimiento de fuertes resistencias sociales, que se reflejó, en la última década, en la emergencia de organizaciones campesinas e indígenas que reclaman sus derechos mediante el conflicto, oponiéndose a aquellas dimensiones del esquema productivo actual vinculadas al modelo agropecuario.

De esta forma, la extensión del agronegocio en la Argentina en los últimos años ha provocado un emergente de conflictos sociales y ambientales que han configurado una serie de movimientos sociales en resistencia permanente. Estos movimientos, con posturas que algunos analistas han denominado "precautorias», se oponen al uso indiscriminado de agroquímicos y fertilizantes y exigen no solo sus derechos a la tenencia de la tierra, sino también un cambio en la orientación del paradigma productivo hacia una producción agroecológica basada en una Reforma Agraria Integral que garantice la soberanía alimentaria. El Plan Estratégico Agroalimentario y Agroindustrial argentino 2010-2020 prevé el incremento de la producción desde las 100 millones de toneladas anuales de granos a las 157 millones de toneladas anuales. Para lograrlo, se deberá continuar con la expansión de la frontera agrícola hacia territorios previamente ocupados e incrementar considerablemente, a su vez, la productividad por hectárea. La primera vía llevará indefectiblemente a la agudización de los conflictos con las poblaciones campesinas y comunidades indígenas sustentadas en la pequeña producción y a la continuación de las políticas de deforestación indiscriminada. La segunda implicará seguir utilizando plaguicidas y herbicidas tóxicos, con la contaminación que se deriva de su aplicación extensiva.

Como un resultado de este esquema analítico y del trabajo aquí desarrollado, se puede proyectar que el proceso de expansión del agronegocio, tal como aquí ha sido caracterizado, redundará en una agudización de los conflictos sociales y ambientales. Si el desmonte y los desalojos violentos, como de aquí se deduce, son una consecuencia directa del establecimiento del «nuevo agro» en la Argentina, se prevé entonces una profundización de la organización y resistencia por parte de los movimientos campesinos indígenas. La visualización de una agudización de las tensiones entre los movimientos sociales y la lógica de la acumulación del capital en la Argentina nos invita entonces a reflexionar críticamente sobre la inevitabilidad del agronegocio como un pilar indiscutible del modelo de desarrollo vigente en la actualidad. En este sentido, se espera que este trabajo contribuya al establecimiento de un diagnóstico y haya aportado herramientas conceptuales que permitan una búsqueda colectiva que exprese la necesidad de construir democráticamente un esquema productivo distinto, que se presente como 
una alternativa sustentable e incluya el punto de vista y las necesidades de quienes, hasta el día de hoy, siguen buscando mediante el conflicto la garantía de sus derechos más elementales.

\section{NOTAS}

1 Junto con las actividades extractivas «tradicionales», que son aquellas que explotan bienes no renovables como el petróleo, el gas o los minerales, en la actualidad el término «neoextractivismo» también engloba a otras actividades productivas sobre bienes «renovables», pero en las que la tasa de extracción se vuelve más alta que la tasa de renovación del recurso, como en el caso del agronegocio (Gudynas, 2009).

2 «El agronegocio refiere a la expansión de los negocios del sector agropecuario y rural y de sus cadenas a partir de relaciones que involucran estructuras contractuales, alianzas o asociaciones ejecutadas principalmente por el sector privado a partir de los productores del sector agropecuario y sostenibles a largo plazo. Estas alianzas involucran tanto a conjuntos asociados de agricultores como a cadenas agroindustriales u otros agentes exógenos» (Santacoloma, P., Suárez, R. y Riveros, H., 2005).

3 El Análisis del Sistema Mundo es una corriente de pensamiento que surge vinculada a la Escuela de los Anales con Fernand Braudel y que en la actualidad incluye a algunos autores como Immanuel Wallerstein, Giovanni Arrighi, Samir Amin y Theotonio Dos Santos, entre otros.

4 La Teoría de la Dependencia es una escuela de pensamiento nacida en Latinoamérica en los años 60 que intenta representar la contracara de las teorías del imperialismo, pero vistas desde la óptica de los países dependientes. Sus principales exponentes fueron Ruy Mauro Marini, Theotonio Dos Santos, André Gunder Frank y Vania Bambirra, entre otros.

5 Luego de la crisis de los años 70 del siglo pasado, una serie de factores históricos, sociales, económicos

y culturales y, por supuesto, ecológicos, colocaron a la cuestión ambiental y al problema de la sustentabilidad ambiental en la primera plana de la agenda de discusión política y científica mundial (Leff, 2006). Existe cierto consenso que identifica en la Conferencia de las Naciones Unidas sobre el Ambiente Humano, realizada en Estocolmo (1972), como un hito a partir del cual la inclusión de las problemáticas ambientales en la agenda mundial se empezó a dar con mayor frecuencia.

6 Como ejemplo de traslatinas asociadas al modelo extractivo exportador se puede citar a la Companhia Vale do Rio Doce (Vale), Petrobras, OAS Ltda., Camargo Correa, Andrade Gutierrez, Odebrecht, Grupo Los Grobo, etc. (Seoane, Taddei, Algranati, 2013)

7 Como un reflejo de esto, la Iniciativa para la Integración de la Infraestructura Regional Suramericana (IIRSA) plantea una serie de obras de infraestructura «estratégicas» que apuntan a facilitar el comercio exterior de commodities como rutas, ferrovías, hidrovías, aeropuertos y puertos (Seoane, Taddei, Algranati, 2013).

8 Con relación al Estado, es preciso señalar que el Estado es también arena de lucha de clases y condensa relaciones de fuerza en su interior que no le permiten tener una función unívoca (Poulantzas, 1985).

9 Esta tensión se puede verificar en las diferencias existentes entre ciertos espacios que promueven el modelo extractivista - como algunas secretarías del Ministerio de Agricultura, Ganadería y Pesca, del Ministerio de Ciencia, Tecnología e Innovación Productiva, del Ministerio de Economía y Finanzas Públicas, el INTA, el SENASA-, y otros sectores que se oponen activamente como algunas secretarías del Ministerio de Desarrollo Social o algunos investigadores del Consejo Nacional de Investigaciones Científicas y Técnicas (CONICET), entre otros sectores que obviamente también incluyen a la sociedad civil. 10 «[...] La sojización creciente está transformándose paulatinamente en monocultivo. Esto significa que no se devuelven los nutrientes al suelo. Al producir una tonelada de soja, se extrae del suelo $16 \mathrm{~kg}$ de calcio por ha, $9 \mathrm{~kg}$ de magnesio, 7 de azufre, 8 de fósforo, 33 de potasio, y 80 de nitrógeno. Mientras tanto, los fertilizantes químicos no devuelven estos nutrientes y tienen un alto índice de acidez. Por eso la sojización va minando aceleradamente las bases sobre las cuales se desarrolla, lo cual le otorga un carácter de economía extractiva» (Anino y Mercatante, 2009, p. 82) 
11 La velocidad con la que se incorporó esta metodología de siembra es sorprendente: de representar menos del 25\% de la superficie sembrada total en 1997 pasó a representar casi el 80\% en 2011, llegando a niveles cercanos al 100\% en provincias como Santiago del Estero, Salta y Corrientes (AAPRESID, 2012). 12 Skill y Grinberg (2013) identifican algunos actores que se posicionan a favor del uso de agroquímicos, que denominan "pragmáticos»; entre ellos cuentan a algunos organismos públicos (SENASA, INTA, MINCyT), empresas transnacionales (Monsanto, organizaciones privadas vinculadas al sector y productores agrarios capitalizados). Para los actores pragmáticos, los agroquímicos representan un insumo fundamental de la agricultura industrial ya que permiten obtener cuantiosos beneficios económicos. Para ellos, el riesgo ambiental y social está subordinado a los beneficios económicos. Por otro lado, identifican actores con una postura «precautoria» que se posicionan en contra del uso de agroquímicos; entre ellos se menciona a organizaciones sociales y socioambientales (pueblos fumigados, Grupo de Reflexión Rural), médicos de pueblos fumigados, vecinos autoconvocados (Madres de Ituzaingó), expertos independientes o pertenecientes al sistema científico (Andrés Carrasco).

1321 millones de hectáreas en Brasil, 14 millones de hectáreas en Argentina y 2 millones de hectáreas en Paraguay (Astarita, 2010)

14 «Solo en la región pampeana habría, en 2008, unos 16 millones de hectáreas afectadas por la acidificación. Esto es un indicador del desequilibrio que genera el monocultivo por pérdida de nutrientes debido a los fertilizantes químicos de alto índice de acidez» (Astarita, 2010, p. 259).

15 En la Argentina la Ley Indígena 23302, el art. 75 inciso 17 de la CN y numerosos tratados y convenios internacionales, como el 169 de la OIT, se establece un reconocimiento del «derecho de los pueblos originarios a vivir en las tierras ocupadas por sus antepasados y a desplegar sus prácticas culturales y modos de vida» (Giarraca, 2007, p. 8). En particular, la conocida «ley veinteañal» establece que si se prueba posesión durante ese lapso de tiempo en forma pacífica, continua e ininterrumpida, se emitirá sentencia ordenándose la inscripción del inmueble a su nombre, en el registro de la propiedad (art. 3999 y ss. del c. civil).

16 Este tipo de desmonte incumple con las medidas de zonificación y de las previsiones de cortinas de viento, lo que tiene efectos sobre el resto del territorio.

17 Desde el MOCASE-VC se denuncia que no existe ningún tipo de control sobre el uso de las reservas de aguas subterráneas. Documento Síntesis sobre reforma agraria integral, en Revista Falta Menos N. ${ }^{\circ}$, 2011.

18 En el caso específico del MOCASE, la organización y lucha para defender el territorio dejó como saldo los asesinatos de Cristian Ferreyra en 2012 y Miguel Galván en 2013.

19 «Reconocer la preexistencia étnica y cultural de los pueblos indígenas argentinos. Garantizar el respeto a su identidad y el derecho a una educación bilingüe e intercultural, reconocer la personería jurídica de sus comunidades, y la posesión y propiedad comunitaria de las tierras que tradicionalmente ocupan; y regular la entrega de otras aptas y suficientes para el desarrollo humano».

20 La Ley 26160 de 2006 declara la emergencia en materia de posesión y propiedad de las tierras que tradicionalmente ocupan las comunidades indígenas originarias del país, cuya personería jurídica haya sido inscripta en el Registro Nacional de Comunidades Indígenas u organismo provincial competente o aquéllas preexistentes. Establece por su parte la suspensión por el plazo de la emergencia declarada, la ejecución de sentencias, actos procesales o administrativos, cuyo objeto sea el desalojo o desocupación de las tierras.

21 En la actualidad, el MOCASE-VC ha desarrollado cooperativas de fabricación de alimentos como queso de cabra, dulce de leche de cabra, escabeches, mermeladas, donde la producción se basa en la agroecología sustentable y el comercio se basa en el concepto de justicia y no de lucro. También tienen talleres de hilado y costura. Individualmente, las familias se dedican a cría de ganado mayor y menor por medio de tierras comunitarias para pastoreo y algunas realizan emprendimientos agroecológicos como el cultivo de zapallo, sandía, maíz, cebolla, la apicultura, etc.

22 La Vía Campesina define a la Soberanía Alimentaria como «el derecho de los pueblos, los países y las uniones de Estados, a definir sus políticas agropecuarias y de producción de alimentos, [...] organizar 
la producción y el consumo de alimentos de acuerdo a las necesidades de las comunidades locales otorgando prioridad a la producción y el consumo locales domésticos, [...] incluye el derecho de proteger y regular su producción nacional agrícola y ganadera, así como a proteger sus mercados domésticos. [...] Campesinos, sin tierra, productores rurales deben tener acceso a tierra, agua, semillas y recursos productivos y servicios públicos adecuados» (Vía Campesina, 2007).

\section{REFERENCIAS}

Anino, P. y Mercatante, E. (2009). Renta Agraria y desarrollo capitalista en Argentina. Lucha de clases, $(\mathrm{s} / \mathrm{n}), 69-110$.

Arrighi, G. (1999). El largo Siglo XX: Dinero y poder en los orígenes de nuestra época. Madrid, España: Akal.

Astarita, R. (2010). Economía política de la dependencia y el subdesarrollo. Tipo de cambio y renta agraria en la Argentina. Bernal, Argentina: Universidad Nacional de Quilmes.

Azpiazu, D., Manzanelli, P. y Schorr, M. (2011). Concentración y extranjerización. La Argentina en la postconvertibilidad. Buenos Aires, Argentina: Capital Intelectual.

Basualdo, E. (2010). Los propietarios de la tierra y las economías de escala, sustentos del paradigma sojero en la Argentina. Desarrollo Económico, 50(197), 3-32.

Carrasco, A., Sánchez, N. y Tamagno, L. (2012). Modelo agrícola e impacto socio-ambiental en la Argentina: monocultivo y agronegocios. La Plata, Argentina: AUGM-Comité de Medio Ambiente.

Centro de Estudios para el Desarrollo Argentino (CENDA) (2010). La anatomía del nuevo patrón de crecimiento y la encrucijada actual. La economía Argentina en el período 2002-2010. Buenos Aires, Argentina: Cara o Ceca/CENDA.

Centro de Investigación y Formación de la República Argentina (2011, febrero 8). Rentabilidad, empleo y condiciones de trabajo en el sector agropecuario. CIFRA-CTA. Recuperado de: http:// www.centrocifra.org.ar /docs/CIFRA\%20-\%20DT\%2008\%20-\%20Rentabilidad,\%20empleo\%20 en\%20el\%20sector\%20.pdf

Delgado Ramos, G. C. (Comp.) (2013). Ecología política del extractivismo en América Latina: casos de resistencia y justicia socio-ambiental. Buenos Aires, Argentina: CLACSO.

Documento Síntesis sobre reforma agraria integral (2011). Falta Menos, (2), 12-15.

Dos Santos, T. (1971). La estructura de la dependencia. En P. Sweezy (Comp.), Economía Política del Imperialismo (pp. 41-64). Buenos Aires, Argentina: Ediciones Periferia.

Giarracca, N. (2007). La tragedia del desarrollo: disputas por los recursos naturales en la Argentina. Sociedad, (3), 1-16.

Gudynas, E. (2009). Diez tesis urgentes sobre el nuevo extractivismo. Contextos y demandas bajo el progresismo sudamericano actual. En CAAP y CLAEE (Eds.), Extractivismo, política y sociedad (pp. 187-224). Quito, Ecuador: CAAP/CLAEE.

Harvey, D. (2004). El nuevo imperialismo: acumulación por desposesión. En L. Panitch, El nuevo desafío imperial (pp. 99-129). Buenos Aires, Argentina: CLACSO.

Kejsefman, I. (2014). El «nuevo» agro argentino: Transformaciones productivas en el sector y la inserción de la Argentina en el actual capitalismo mundial (1990-2012). Mimeo (s/d).

Leff, E. (2006). La ecología política en América Latina. Un campo en construcción. En H. Alimonda (Comp.), Los tormentos de la materia. Aportes para una ecología política latinoamericana (pp. 
21-40). Buenos Aires, Argentina: Consejo Latinoamericano de Ciencias Sociales (CLACSO). Marx, K. (2000). El Capital. Madrid, España: Akal.

Merlinsky, G. (Comp.) (2013). Cartografías del conflicto ambiental en la Argentina. Buenos Aires, Argentina: Fundación CICCUS.

O’Connor, J. (2001). Causas naturales. Ensayos de marxismo ecológico. México DF, México: Siglo XXI.

Osorio, J. (2004). Crítica de la economía vulgar Reproducción del capital y dependencia. México DF, México: Miguel Ángel Porrua, UAZ.

Poulantzas, N. (1985). Las clases sociales en el capitalismo actual. México DF, México: Siglo XXI.

Santacoloma, P., Suárez, R. y Riveros, H. (2005). Fortalecimiento de los vínculos de agronegocios con los pequeños agricultores. Estudios de caso en América Latina y el Caribe. Servicio de Gestión, Comercialización y Finanzas Agrícolas (AGSF), (Documento ocasional 4), p. 71.

Seoane, J., Taddei, E. y Algranati, C. (2013). Extractivismo, despojo y crisis climática. Buenos Aires, Argentina: Herramienta, El Colectivo.

Skill, K. y Grinberg, E. (2013). Controversias sociotécnicas en torno a las fumigaciones con glifosato en Argentina. Una mirada desde la construcción social del riesgo. En G. Merlinksy (Comp.), Cartografías del conflicto ambiental en Argentina (pp. 91-118). Buenos Aires, Argentina: Fundación CICCUS.

Svampa, M. (2012). Consenso de los Commodities, Giro Ecoterritorial y Pensamiento crítico en América Latina. Buenos Aires; Argentina: OSAL.

Teubal, M. (2006). Expansión del modelo sojero en la Argentina. De la producción de alimentos a los commodities. Realidad Económica, (220), 71-96.

Wallerstein, I. (2006). Análisis de Sistema-Mundo. México DF, México: Siglo XXI.

La voz de los campesinos y campesinas del mundo (2007, julio 11). Vía Campesina. Recuperado de: http://viacampe sina.org/es/index.php/organizaciainmenu-44/iquisomos-mainmenu-45? start=1

Astarita, R. (2008, julio 9). Globalización y desarrollo capitalista en el agro. Rolando Astarita. Recuperado de: http:// rolandoastarita.com/1Globalizacion-agro.htm

Aranda, D. (2013, mayo 25). La década extractiva. ComAmbiental. Recuperado de http://www.comambiental.com.ar /2013/05/la-decada-extractiva.html 
